\title{
Development of a non-tissue adherent neurosurgical patty and an ex vivo testing system to evaluate adherent characteristics
}

\author{
Manabu Kinoshita, MD, PhD, ${ }^{1,3}$ Mai Taniguchi, BEng, ${ }^{2}$ Masatoshi Takagaki, MD, ${ }^{1}$ \\ Nobuhisa Seike, BEng, ${ }^{2}$ Naoya Hashimoto, MD, PhD, ${ }^{3}$ and Toshiki Yoshimine, MD, PhD ${ }^{3}$ \\ 'Department of Neurosurgery, Osaka Medical Center for Cancer and Cardiovascular Diseases; ${ }^{2}$ Kawamoto Corporation; and \\ ${ }^{3}$ Department of Neurosurgery, Osaka University Graduate School of Medicine, Osaka, Japan
}

\begin{abstract}
Neurosurgical patties are the most frequently used instruments during neurosurgical procedures, and their high performance is required to ensure safe operations. They must offer cushioning, water-absorbing, water-retaining, and non-tissue adherent characteristics. Here, the authors describe a revised neurosurgical patty that is superior in all respects to the conventional patty available in Japan. Patty characteristics were critically and scientifically evaluated using various in vitro assays. Moreover, a novel ex vivo evaluation system focusing on the adherent characteristics of the neurosurgical patty was developed. The proposed assay could provide benchmark data for comparing different neurosurgical patties, offering neurosurgeons objective data on the performance of patties. The newly developed patty was also evaluated in real neurosurgical settings and showed superb performance during various neurosurgical procedures.
\end{abstract}

http://thejns.org/doi/abs/10.3171/2014.9.JNS14347

KEY WORDS neurosurgical patty; neurosurgical device; surgical device; surgical technique

$\mathrm{N}$ EUROSURGiCAL patties, also known as cottonoids, are the most frequently used instruments during neurosurgical procedures. They have a broad array of applications in neurological procedures, from neuronal tissue protection to securing the resection plane..$^{1,3}$ The feature of low adhesiveness is as important as the moistureretaining and cushioning characteristics. As neurosurgical patties provide the primary interface between metal neurosurgical devices and neuronal tissues, adhesive interactions with the tissues should be minimized to maximize the protective function and to reduce neuronal tissue damage when removing patties from the surgical field.

In this study, a thick neurological patty was developed to meet the above-mentioned demands while preserving radiographic detectability. In vitro and ex vivo experiments were performed to objectively assess the improved functionality of and the initial clinical experience with this patty during neurosurgical operations.

\section{Methods \\ Neurosurgical Patties}

Two types of neurosurgical patties were assessed in this study. The control patty was the conventional, 0.5 -mm-thick neurosurgical patty made of cupra rayon filament. This product is manufactured by attaching multiple nonwoven fabrics using a high-pressure water jet stream. A radiographically visible marker is woven into the body of the patty. The newly developed patty was 1-mm-thick and made from cupra rayon filament, with the entire marker thread made to be radiographically visible and welded to the end of the patty body. The manufacturing procedure differed from that of the conventional version in that multiple nonwoven fabrics were attached by mechanical interlacing. Multiple nonwoven fabrics were penetrated by needles, which cause fluffy fabric layers to loosely twine. This manufacturing 
procedure contrasts with previous methods, which cause each layer to be compressed by a high-pressure water jet stream. The revised manufacturing process ensures enhanced cushioning by the patties because of the loose attachment of each fabric layer. Both patties were $3 \times$ $6 \mathrm{~cm}$ in size and were developed and provided by the Kawamoto Corporation (Fig. 1A).

\section{In Vitro Assessments}

Moisture-retaining and cushioning characteristics were assessed using in vitro experiments. Cushioning characteristics were assessed by measuring the compressive capabilities of the patties, as calculated using the following equation: $\mathrm{Cr}=\left(\mathrm{T}_{0}-\mathrm{T}_{1}\right) / \mathrm{T}_{0}$, where $\mathrm{Cr}$ stands for compressive capability, $\mathrm{T}_{0}$ for the thickness under "normal pressure" (50 grams-force $\left.[\mathrm{gf}] / \mathrm{cm}^{2}\right)$, and $\mathrm{T}_{1}$ for the thickness under "high pressure" (300 gf $\left./ \mathrm{cm}^{2}\right)$.

By measuring the amount of water that the patties could absorb, we assessed moisture-absorption characteristics. The absorbed amount of water was then divided by the surface area of the patty. Water-retention capability was also evaluated by measuring the remaining absorbed water within the patties in a time-dependent manner at $23^{\circ} \mathrm{C}$ and $40 \%$ humidity. Five samples of each patty were assessed for all experiments, and the mean \pm standard deviation was reported. All statistical analysis was performed using the Student t-test in Microsoft Excel. A p value < 0.05 was set as statistically significant.
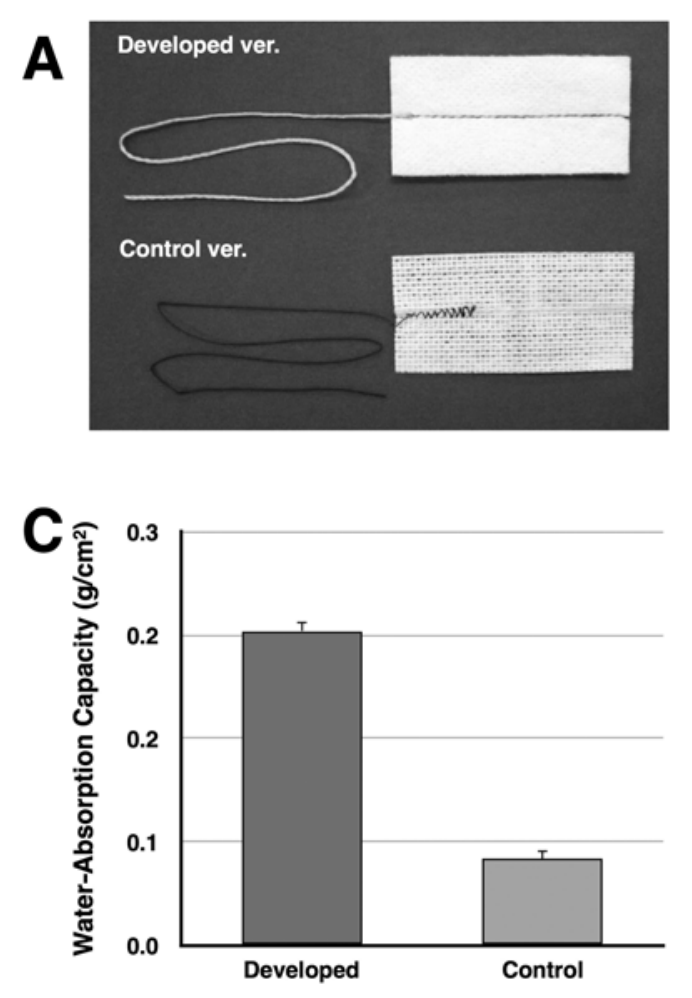

\section{Ex Vivo Assessments}

Adhesive characteristics of patties were assessed using ex vivo experiments. Patties moistened with water were placed on a 5-g piece of calf liver for 1 hour under pressure of $10 \mathrm{gf} / \mathrm{cm}^{2}$ at $23^{\circ} \mathrm{C}, 40 \%$ humidity. Subsequently, the marker thread was pulled up at $100 \mathrm{~mm} / \mathrm{min}$ to slowly remove the patty from the piece of liver. The process was recorded, and tensile load was measured throughout the procedure until the patty was completely removed from the liver piece. Maximum tensile load was also calculated using 20 samples for each group, and the mean \pm standard deviation was reported.

Radiographic visibility was also evaluated using plain skull radiography $(70 \mathrm{kV}, 100 \mathrm{~mA})$ with the patty placed at the side of a cadaveric human head.

\section{Initial Clinical Experience}

Three different surgeons (M.K., M.T., and N.H.) tested both types of patties during routine neurosurgical procedures. These procedures included both brain tumor removal and cerebral aneurysm clipping surgeries. Overall performance of both patties was evaluated during surgery to determine whether the newly developed patty was suitable for use in neurosurgical procedures. The internal review board approved the use of clinical data for this study.

\section{Results}

The newly developed patty is twice as thick as the con-
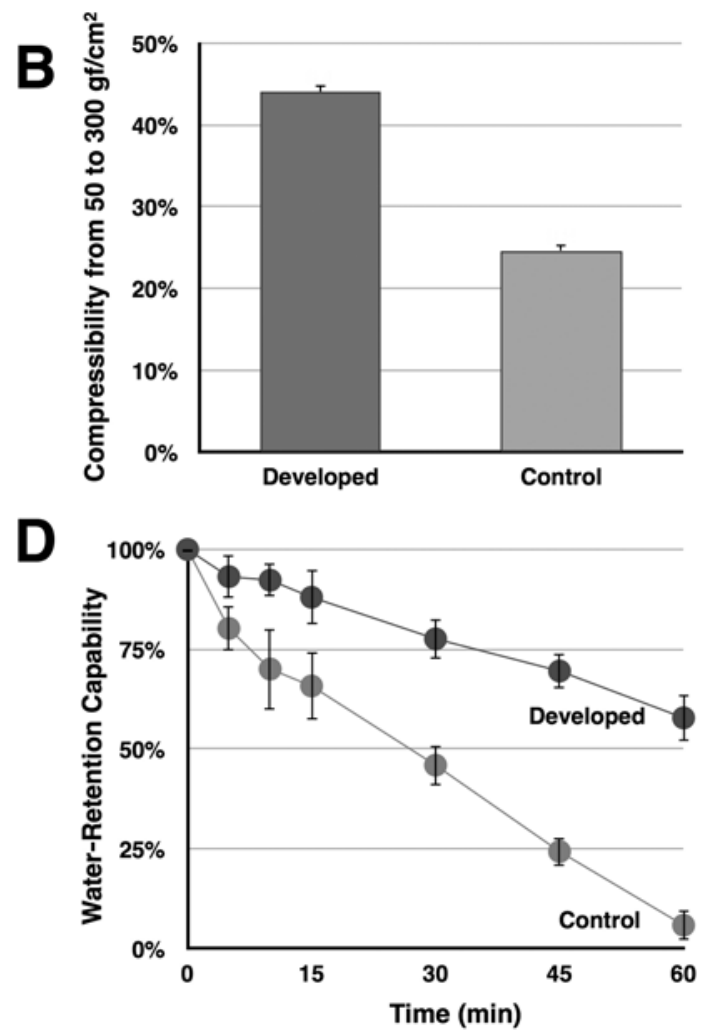

FIG. 1. In vitro examinations of the conventional (control) and newly developed neurosurgical patties. Overall appearance of both types of patties (A). Data for compressibility (B), water-absorption capacity (C), and water-retention capability (D). All values are expressed as the mean \pm standard deviation. ver. $=$ version. 
ventional version. The marker thread itself is radiographically visible, which makes the thread somewhat stiffer. However, the new patty exhibits a much more uniform tissue contact plane, as the radiographically visible marker is not located within the patty as in the conventional version (Fig. 1A). Cushioning characteristics were nearly doubled in the new version compared with the conventional patty (44.1 vs $24.6 \%$, p < 0.001; Fig. 1B). Because of its thickness, the new patty had a nearly tripled waterabsorption capacity (Fig. 1C), and its water-retention capability was significantly improved $\left(0.23 \mathrm{vs} 0.06 \mathrm{~g} / \mathrm{cm}^{2}\right.$, $\mathrm{p}<0.001$; Fig. 1D). Improvements in water-retention capability were significant after as little as 5 minutes $(\mathrm{p}<$ $0.001)$, and the difference was significantly large at 60 minutes after starting the test $(\mathrm{p}<0.0001$; Fig. 1D). These results suggested that the basic functionality of the newly developed patty exceeded that of the conventional version.

Next, adhesive characteristics of both types of patties were examined in an ex vivo environment. Adhesiveness of the patties was simulated on a piece of calf liver (Fig. 2A). As clearly shown in Fig. 2B, conventional patties showed strong adhesion to the liver piece. This negative characteristic was significantly improved with the newly developed version. A $39 \%$ reduction $(p<0.0001)$ in tensile load was achieved (Fig. 2C and D), and the newly devel- oped patties detached more smoothly from the liver piece than the conventional version (Video 1).

VIDEO 1. Traction test. The adhesive property of the patties was tested using a piece of calf liver to mimic brain tissue. The newly developed patty can easily detach from the mimicked brain tissue while the conventional version cannot $(00: 11)$. Copyright Osaka Medical Center for Cancer and Cardiovascular Diseases. Published with permission. Click here to view with Media Player. Click here to view with Quicktime.

Radiographic visibility of the new patty was also satisfactory thanks to the long, firm radiographically visible marker threads (Fig. 3).

Finally, the newly developed patties were used in various neurosurgical procedures to, for example, protect neural tissues from damage caused by metal neurosurgical devices, such as suction devices, brain retractors, and bipolar coagulators. They were also used to secure resection planes during brain tumor surgery. "Field testing" of the newly developed patty was critically evaluated by experienced neurosurgeons. In general, the new patty showed performance superior to that of the conventional patty, completely replacing the conventional version except for use in extremely narrow surgical fields such as in dissecting perforating arteries from cerebral aneurysms. The water-absorbing and moisture-retaining features of the newly developed patty performed extremely well for securing
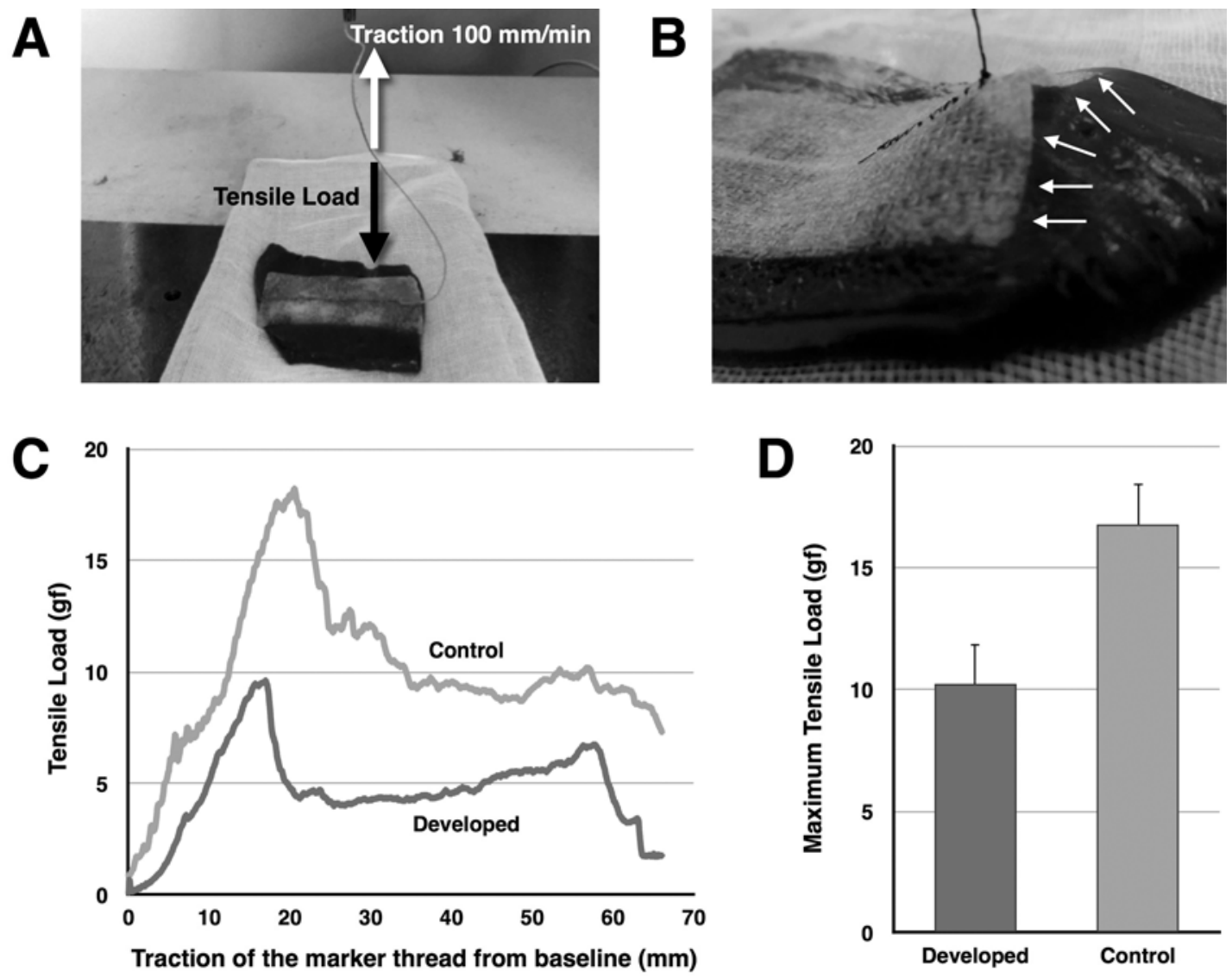

FIG. 2. Ex vivo experiments for evaluating the adhesive properties of both types of patties. The experimental setting (A). Adhesion of patties to a piece of calf liver (mimicking cerebral tissue) can be evaluated both visually (B, arrows) and numerically (C and D). Maximum tensile loads are reported as the mean \pm standard deviation. 


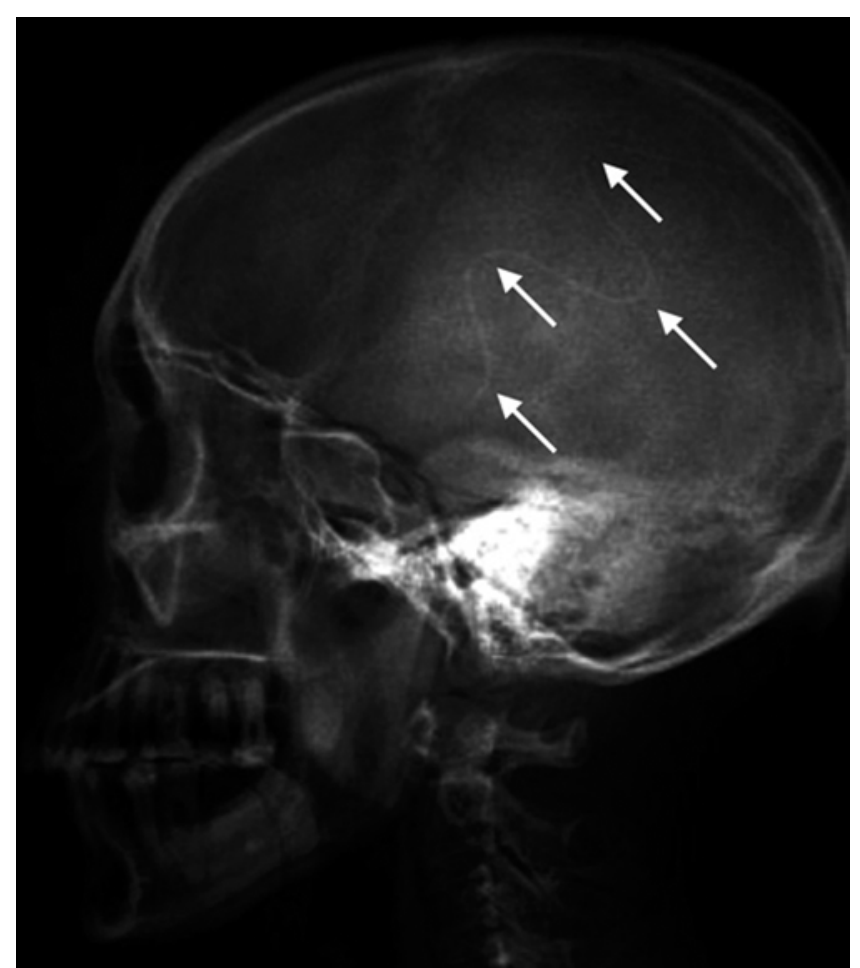

FIG. 3. Radiographic visibility was evaluated on plain skull radiography, with the new patty placed at the side of a cadaveric human head. Arrows indicate the patty marker thread.

tumor resection planes. This property also reduced the number of patties exchanged for dried-out patties during surgery. In addition, the new patty's less adhesive property did not affect its hemostatic performance. As can be seen in a video (Video 2 ), the newly developed patty performed well for hemostasis during brain tumor resection (for example, glioblastoma).

VIDEO 2. Hemostasis efficiency of the newly developed patty was tested during glioblastoma removal. Satisfactory hemostatic performance can be seen (00:32-03:37). Copyright Osaka Medical Center for Cancer and Cardiovascular Diseases. Published with permission. Click here to view with Media Player. Click here to view with Quicktime.

And again, thanks to the patty's less adhesive property, smooth removal from brain tissues at the end of procedures was facilitated (Video 3).

VIDEO 3. Nonadherent performance of the newly developed patty during various neurosurgical procedures. The low adhesive property of the patty was confirmed. Copyright Osaka Medical Center for Cancer and Cardiovascular Diseases. Published with permission. Click here to view with Media Player. Click here to view with Quicktime.

\section{Discussion}

Neurosurgical patties are essential and one of the most important instruments used during neurosurgical procedures. In many cases, these patties become the primary interface between metal neurosurgical instruments and neural tissues. They are used for hemostasis, neural tissue protection, and fluid absorption to secure a well-visualized surgical field. ${ }^{1}$ They must possess cushioning, moistureretaining, and non-tissue adherent characteristics. These functions are required to achieve a precise, stress-less, and well-visualized microscopic neurosurgical field. While patties are routinely used in various neurosurgical procedures, the literature referring to their proper use is scant, and, to the best of our knowledge, no scientific evaluations of neurosurgical patties have been reported.

In the current report, we describe a newly developed neurosurgical patty, and the above-mentioned key characteristics were scientifically and critically evaluated in comparison with the conventional cupra rayon neurosurgical patty that is commercially available in Japan. Both in vivo and ex vivo assessments confirmed that the newly developed version outperformed the conventional patty from all 3 key perspectives, indicating that it could replace the conventional version for use in neurosurgical procedures. Although most vendors worldwide claim that their neurosurgical patties are nonadherent, the issue of patty-tissue interactions is encountered daily by neurosurgeons. ${ }^{3}$ This issue was previously pointed out in the literature, and authors confirmed that when patties were placed on cerebral tissue for more than 15 minutes, all tested patties stuck to the tissue, resulting in some degree of trauma to underlying cerebral tissue on removing the patty. ${ }^{3}$ We encountered the same thing with the conventional patty tested in our study. Although the manufacturer of our tested patties differed from that of the patties in the study by Menovsky et al., ${ }^{3}$ we also frequently experienced conventional patties interacting with cerebral tissues during neurosurgical procedures. We solved this issue by enhancing the water-absorbing and moisture-retaining features of the new patty (Fig. 1). This enhancement was achieved mainly through the increased thickness of the new patty compared with that of the conventional version ( $1 \mathrm{vs} 0.5 \mathrm{~mm}$ ) and through the revised manufacturing process for attaching multiple cupra rayon fabric layers. The revised manufacturing process ensured the original 3D structure of the nonwoven fabrics, which had been compromised by previous manufacturing procedures. Although the thickness was only doubled, this revision led to a tripled water-absorption capacity and 10 -fold (58\% vs $6 \%$ ) water-retention capacity when compared at 60 minutes post-water absorption. These improvements dramatically reduced adhesiveness, as can be seen in both the ex vivo testing (Video 1) and the positive results in actual neurosurgical procedures, leading to reduced adhesion of patties to cerebral tissues and easier removal of patties from surgical sites (Video 3 ) without compromising the hemostatic capability of the patties (Video 2). In addition, radiographic detectability was satisfactory (Fig. 3), representing a feature that is considered extremely important to avoid accidental patty retention. ${ }^{2}$

On the other hand, the thickness of the new version (1 $\mathrm{mm}$ ) could cause issues in some cases. In those cases with an extremely narrow surgical field, such as cerebral aneurysm surgery, thick patties interfered with the surgical field, leading surgeons to prefer the use of conventional patties rather than the newly developed version. Although this thickness could be a limitation in rare situations, we strongly believe that the newly developed patty is greatly 
superior to conventional patties in most neurosurgical procedures and especially in brain tumor surgeries; however, the advantages of the new patty should be confirmed from both a surgical utility and a cost-effectiveness perspective by others in their routine neurosurgical practice.

It should also be noted that this investigation was unique in proposing an ex vivo simulation of the adhesive properties of neurosurgical patties. Although many manufacturers advertise their patties as "non-adhesive" or "nonstick," there is currently no universal system for assessing the adhesive properties of neurosurgical patties. In a previous study, ${ }^{3}$ patty adhesiveness was assessed according to the subjective impressions of various neurosurgeons or subjective scoring of traumatic brain injuries to cerebral tissues caused by patty adhesion during surgery. Objective assessments of the adhesive properties of the patties were not possible until they were actually used in real clinical settings, which required the actual use of patties in invasive surgical procedures even though the surgeons were unaware of the patty's adhesive property. In the present study, we used pieces of calf liver tissue to mimic cerebral tissue and numerically measured the adhesive properties of patties (Fig. 2 and Video 1). Our assay system could be used to evaluate the adhesive characteristic of patties in a noninvasive ex vivo manner that could provide benchmark data for different neurosurgical patties. Such information would allow neurosurgeons to compare the objective performance of different patties before using them for surgery, which is considered to save unnecessary field testing of new patties.

\section{Conclusions}

A revised version of the conventional neurosurgical patty was developed with enhanced water-absorption and moisture-retaining capabilities and decreased tissue adhesiveness. The newly developed patty also showed superb performance in real neurosurgical procedures. The proposed ex vivo patty tissue adhesion test could provide benchmark data for various neurosurgical patties and could offer a reliable method for objectively evaluating the performance of neurosurgical patties.

\section{References}

1. Hernesniemi J, Niemelä M, Karatas A, Kivipelto L, Ishii K, Rinne J, et al: Some collected principles of microneurosur- gery: simple and fast, while preserving normal anatomy: a review. Surg Neurol 64:195-200, 2005

2. Marquardt G, Rettig J, Lang J, Seifert V: Retained surgical sponges, a denied neurosurgical reality? Cautionary note. Neurosurg Rev 24:41-43, 2001

3. Menovsky T, De Ridder D, de Vries J: Neurosurgical patties and their intraoperative interaction with neural tissue. Surg Neurol 71:326-329, 2009

\section{Author Contributions}

Conception and design: Kinoshita, Taniguchi. Acquisition of data: Kinoshita, Taniguchi, Takagaki, Hashimoto. Analysis and interpretation of data: Kinoshita, Taniguchi, Takagaki, Hashimoto. Drafting the article: Kinoshita, Taniguchi, Seike, Hashimoto, Yoshimine. Critically revising the article: Kinoshita, Takagaki, Seike, Hashimoto, Yoshimine. Approved the final version of the manuscript on behalf of all authors: Kinoshita. Administrative/technical/material support: Yoshimine. Study supervision: Kinoshita.

\section{Supplemental Information Videos}

Video 1, Media Player. http://mfile.akamai.com/21490/wmv/ digitalwbc.download.akamai.com/21492/wm.digitalsource-naregional/jns14-347_video_1.asx.

Video 1, Quicktime. http://mfile.akamai.com/21488/mov/ digitalwbc.download .akamai.com/21492/qt.digitalsource-global/ jns14-347_video_1.mov.

Video 2, Me dia Player. http://mfile.akamai.com/21490/wmv/ digitalwbc.download.akamai.com/21492/wm.digitalsource-naregional/jns14-347_video_2_NEW.asx.

Video 2, Quicktime. http://mfile.akamai.com/21488/mov/ digitalwbc.download.akamai.com/21492/qt.digitalsource-global/ jns14-347_video_2_NEW.mov.

Video 3, Media Player. http://mfile.akamai.com/21490/wmv/ digitalwbc.download.akamai.com/21492/wm.digitalsource-naregional/jns14-347_video_3.asx.

Video 3, Quicktime. http://mfile.akamai.com/21488/mov/ digitalwbc.download.akamai.com/21492/qt.digitalsource-global/ jns14-347_video_3.mov.

\section{Correspondence}

Manabu Kinoshita, Department of Neurosurgery, Osaka Medical Center for Cancer and Cardiovascular Diseases, 1-3-3 Nakamichi, Higashinari-ku, Osaka 537-8511, Japan. email: mail@manabukinoshita.com. 